\title{
Surface Conditions Analysis of Polymeric Insulators Under Contamination Effects
}

\author{
N. M. Rozi ${ }^{1}$, N. A. Othman ${ }^{1 *}$, Z. Adzis ${ }^{2}$, H. Kamarden' ${ }^{2}$ R. A. Rahman', \\ M. N. R. Baharom ${ }^{1}$, M. S. Kamarudin ${ }^{1}$
}

${ }^{1}$ Department of Electrical Power Engineering, Faculty of Electrical \& Electronic Engineering, Universiti Tun Hussein Onn Malaysia (UTHM), 86400 Batu Pahat, Johor, MALAYSIA

${ }^{2}$ School of Electrical Engineering, Faculty of Engineering, Universiti Teknologi Malaysia (UTM), 81310 Johor Bahru, Johor, MALAYSIA

*Corresponding Author

DOI: https://doi.org/10.30880/ijie.2020.12.02.017

Received 29 December 2019; Accepted 27 January 2020; Available online 28 February 2020

\begin{abstract}
A good polymer insulator can maintain the hydrophobic surface properties. However, polymer insulator is exposed to the environment which may lead to the deposition of rain water or factory oil. Oil is categorized as hydrophobic while water has a hydrophilic feature which when deposit on the insulator surface, it may affect the performance of insulator. Therefore, this paper studies the effect of water and oil contamination on current density and space charge distribution along $15 \mathrm{kV}$ polymeric insulators particularly ethylene propylene-diene monomer (EPDM) and silicone rubber (SiR). A three-dimensional model of polymeric insulator was designed using a finite element software to evaluate the current density and space charge distribution while the experimental works was conducted in the laboratory to measure the charge distribution only. The results reveal that both current density and charge distribution is affected depend on the conductivity of contamination conditions. Both results extracted from simulation and experimental is in agreement where the EPDM insulator have higher amplitude of charge compared to $\mathrm{SiR}$ insulator.
\end{abstract}

Keywords: current density, charge distribution, silicon rubber, EPDM

\section{Introduction}

It is well known that insulation prevent the flow of current on the conductor. There are mainly three types of insulators used for transmission lines particularly glass, porcelain and polymeric insulators. Glass and porcelain insulators are the earliest insulators used for outdoor applications that offers many advantages such as very high mechanical strength under pressure and hardness. Meanwhile, polymeric insulators are worldwide used for outdoor applications due to its better characteristic than porcelain and glass (Marungsri, Onchantiek and Oonsivilai, 2008)(Jamail, Piah, Muhamad, Zainir, Kasri, and Kamarudin, 2013). The main advantages of polymeric insulators over porcelain and glass insulators are lightweight, durable, and maintain hydrophobic surface properties (Norddin et al., 2013). Although the polymeric is lightweight and durable, it is also undeniable that the surface of polymeric is often exposed to the surrounding especially contamination source which can affect the polymeric performance (Looms and Chapman, 1991) (Moussavi, Sheikhdoragh and Shayegani-Akmal, 2012).

There are many types of polymeric insulators but as ethylene propylene-diene monomer (EPDM) and silicone rubber (SiR) are the most widely used insulator in HV application (Khan, Amin and Ahmad, 2018). The schematic diagram of $\mathrm{SiR}$ and EPDM insulators are illustrated in Fig. 1 and Fig. 2, respectively. Both insulators have different dielectric strength levels (Mansor, Hamzah, Kamarol, and Mariatti, 2014) where SiR is known to have a better dielectric strength 
compared to EPDM. Meanwhile, EPDM also has a unique combination of physical properties that suitable for outdoor performance but less sensitivity to contamination (Kroschwitz, 1990). The presence of contamination layer either small or large on the polymeric surface is believed may weaken the insulator performance. Therefore, in this paper, three dimensional (3D) COMSOL model was developed based on the real geometrical dimensions available in the laboratory with the purpose to investigate the effect of contamination layer on the current density and charge distribution along the insulator surface.

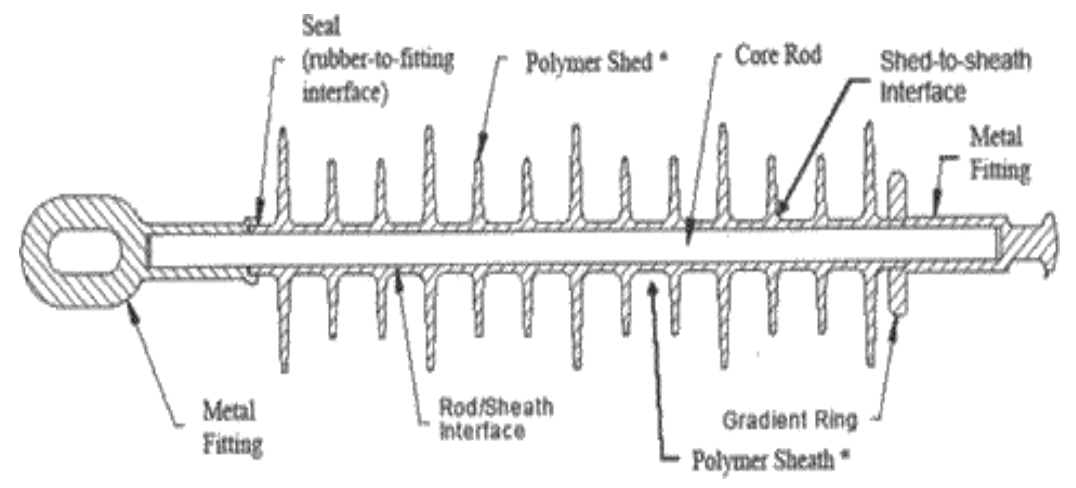

Fig. 1 - Schematics diagram for SiR

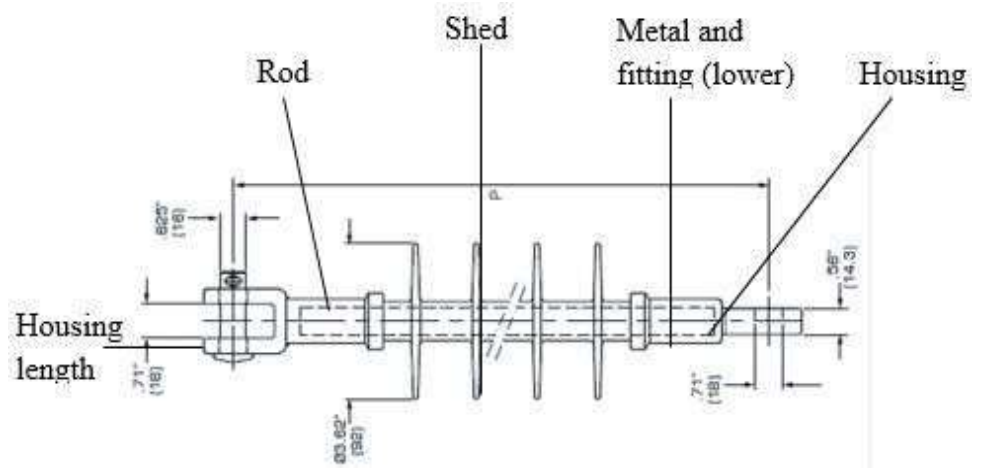

Fig. 2 - Schematics diagram for EPDM

\section{Significant Study on Current Density and Charge Distribution}

In the the design process, the behaviour of current density should be the main consideration to ensure it give the satisfaction in lifetime performance. Based on literature, charge distribution is a charge that is scattered across the surface of the insulator while the space charge is assembled in one place only. However, the existence of space charge can affect the current since the current was directly proportional to the space charge. The relationship between current density and current is given in equation Error! Reference source not found.) where $J$ is current density, $A$ is total area and $I$ is total current flow.

$$
J=\frac{I}{A}
$$

Referring to equation Error! Reference source not found.), the current density is inversely proportionally to the total area while current is directly proportional to the current density. Since the presence of space charge is related with the existence of varies conductivity in the insulation material (Othman, Piah and Adzis, 2017), the space charge density effect can be predicted based on the equation Error! Reference source not found.). Not only that, the change in conductivity also affects the current density distribution as shown by equation Error! Reference source not found.).

$$
\begin{gathered}
\rho=J \nabla\left(\frac{\varepsilon_{r} \varepsilon_{0}}{\delta}\right) \\
J=\delta E
\end{gathered}
$$

Where

$\rho_{\text {is the space charge density }}$ 
$J$ is current density

$E$ is electric field

$\varepsilon_{r}$ is the relative permittivity of material

$\varepsilon_{o}$ is the permittivity of free space

$\delta$ is the conductivity of the material

Based on aforementioned equations, it can be concluded that the presence of conductivity may affect the space charge density value and current density as well. This effect can be seen especially when the value of the conductivity is varies. Therefore, in this paper, the variation of conductivity is analysed by modelling a layer of water and oil on the insulators surface which act as the contamination layer. Moreover, the water and oil were chosen as contamination layer to represent the effect of hydrophobic and hydrophilic properties acting on the surface of polymeric insulators.

\section{Materials and Methods}

\subsection{Insulator Model and Simulation Parameters}

Fig. 3 shows two types of insulators particularly SiR and EPDM that modelled with voltage rated of $15 \mathrm{kV}$ using 3D COMSOL software. Both insulators were modelled in clean and contaminated conditions where a uniform layer of water and oil was coated on the entire surface of insulators.

Table 1 shows the insulator material properties based on relative permittivity and conductivity itself. Meanwhile, the dimension for both insulators for completing the design model in COMSOL software is shown in Table 2.

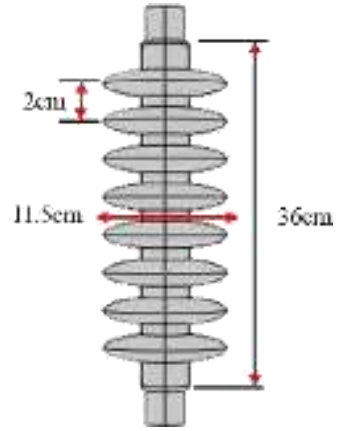

(a)

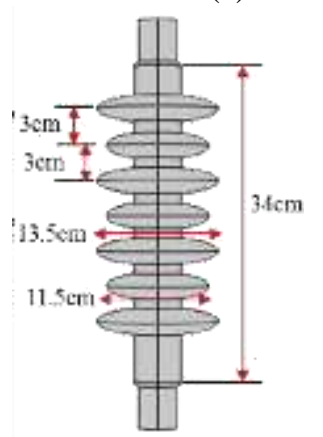

(b)
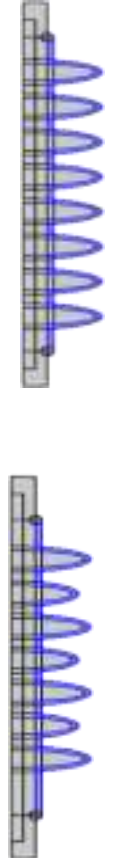

Fig. 3 - Model insulators (a) SiR; (b) EPDM

Table 1 - Material properties of COMSOL

\begin{tabular}{ccc}
\hline Properties & $\begin{array}{c}\text { Relative } \\
\text { permittivity, } \\
\left(\boldsymbol{\varepsilon}_{\boldsymbol{r}}\right)\end{array}$ & $\begin{array}{c}\text { Conductivity, } \\
(\boldsymbol{\mu}) \mathbf{s} / \mathbf{m}\end{array}$ \\
\hline SiR & 4.3 & $10^{-12}$ \\
\hline FRP core & 7.2 & $10^{-12}$ \\
\hline Forged steel & 1 & $5.9 \times 10^{7}$ \\
\hline Polypropylene & 2.2 & $1.12 \times 10^{-7}$ \\
\hline Water & 80 & $5.5 \times 10^{-6}$ \\
\hline Oil & 2.2 & $2000 \times 10^{-12}$ \\
\hline
\end{tabular}


Table 2 - Insulator dimensions

\begin{tabular}{lcc}
\hline $\begin{array}{l}\text { Insulator } \\
\text { geometry }\end{array}$ & SiR & EPDM \\
\hline $\begin{array}{l}\text { Number of } \\
\text { sheds }\end{array}$ & 8 & 7 \\
Arc sheds & $360 \mathrm{~mm}$ & $340 \mathrm{~mm}$ \\
Shed diameter & $115 \mathrm{~mm}$ & $135 \mathrm{~mm}$, \\
Sheath diameter & $20 \mathrm{~mm}$ & $115 \mathrm{~mm}$ \\
Service voltage & $15 \mathrm{kV}$ & $15 \mathrm{~mm}$ \\
\hline
\end{tabular}

\subsection{Experimental Works}

Fig. 4 exhibits the insulator setup in the chamber where insulator was placed with stainless steel mesh and charge sensor was connected with the mesh. The stainless-steel mesh with holes size of $1 \mathrm{~cm} \mathrm{x} 1 \mathrm{~cm}$ was used as a medium to capture the charge on polymeric insulator surfaces. The material used for the mesh was similar but it was in a different size for different insulator types. The size of mesh with diameter and height is $24 \mathrm{~cm} \mathrm{x} 36 \mathrm{~cm}$, respectively was used for an alternate sheds insulator; while for a straight sheds insulator the diameter was reduced by $2 \mathrm{~cm}$ with the height of mesh is maintained in $36 \mathrm{~cm}$. The equipment was arranged in the lab based on the procedures in the lab sheet to produce HVAC.

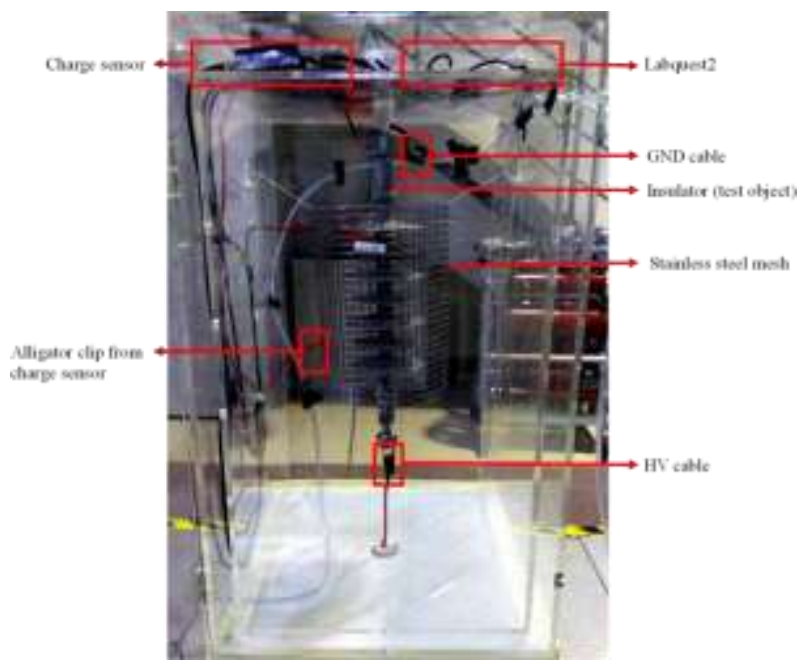

Fig. 4 - Insulator setup

\section{Results and Discussion}

The current density and charge distribution were simulated by setting all related parameters that is needed. Simulation and experimental results were compared between silicone rubber (SiR) and ethylene propylene-diene monomer (EPDM) insulator mainly on the current density and charge distributions on the surface insulator. However, in simulation, SiR and EPDM insulator are discussed in two different surfaces i.e. clean and contaminated conditions while the experiments are tested only under clean surface condition to obtain charge distribution on the insulator surface.

\subsection{Simulation Results for SiR Insulator}

Fig. 5 (a) shows the current density contour plot of $15 \mathrm{kV} \mathrm{SiR}$ insulator under clean and contaminated conditions. It is accepted from equation Error! Reference source not found. that electric field is directly proportional to current density. Therefore, the present findings on current density can be considered as similar to (Muniraj and Chandrasekar, 2012)(Sarang, Lakdawala and Basappa, 2009) where maximum electric field stress occur at the HV side under clean dry condition.

Meanwhile, the electric current density for contaminated insulator seems increased with the presence of water as contamination especially on the trunk portion between sheds. Based on result in Fig. 5 (b), the existence of water has increased the conductivity along the sheath on SiR which led to the increment of electric field distribution at the same location. The present findings is in agreement with (Davidson, 2017)(Nekahi, McMeekin and Farzaneh, 2015) which concluded that the current density is depends on the conductivity of contamination. 


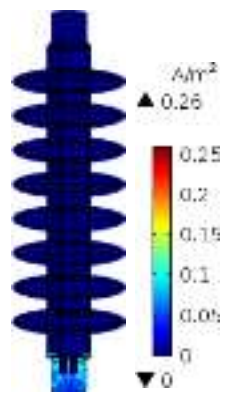

(a)

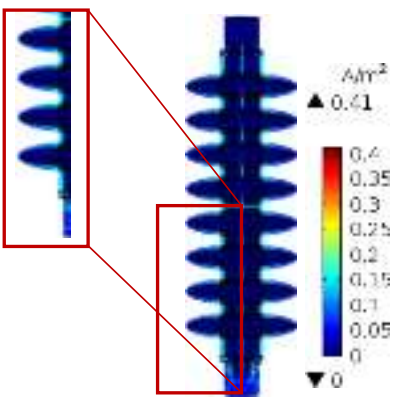

(b)

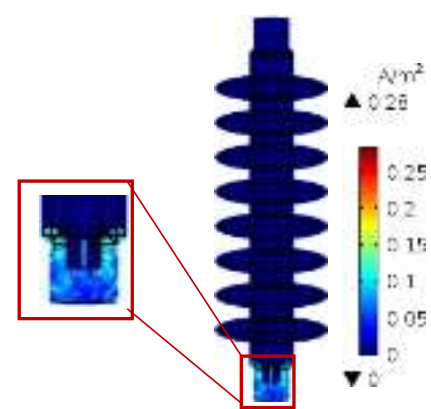

(c)

Fig. 5 - Current density contour plot for (a) clean; (b) water; and (c) oil surface condition for SiR insulator

It is observed that that maximum electric current density occurs at the HV end when oil was coated as the contamination layer as circled in Fig. 6 (c). The presence of oil is believed led to increment of temperature on a certain part of the insulation. This is due to the conductivity of steel material in insulation increasing at the critical point area (Mazli, Jamail and Othman, 2017) (Shazly et al, 2017).

The result in Fig. 6 (c) is in agreement with (Rahman and Thottappillil, 2002) where the surface charge does not depend on hydrophobic properties but it depends on the material and filling process. It can be explained by using tribocharging concept (I. R. M. Association, 2017) whereby when two different materials touch each other, electrostatic charges can be induced. In this case, the electrons in the oil is believed move to the SiR insulator surface and therefore many charges are accumulated on the shed of the insulation when it touches each other.

\subsection{Simulation Results on Space Charge Density for SiR Insulator}

Fig. 6 shows the space charge density under clean and contaminated surface condition for SiR insulator.

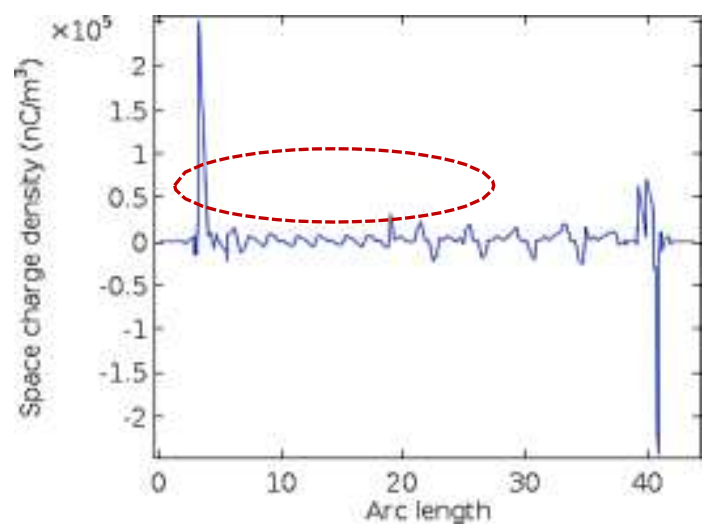

(a)

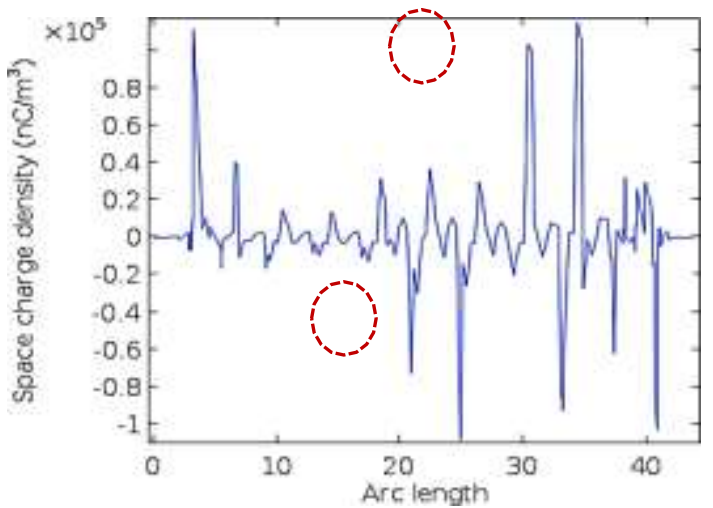

(b) 


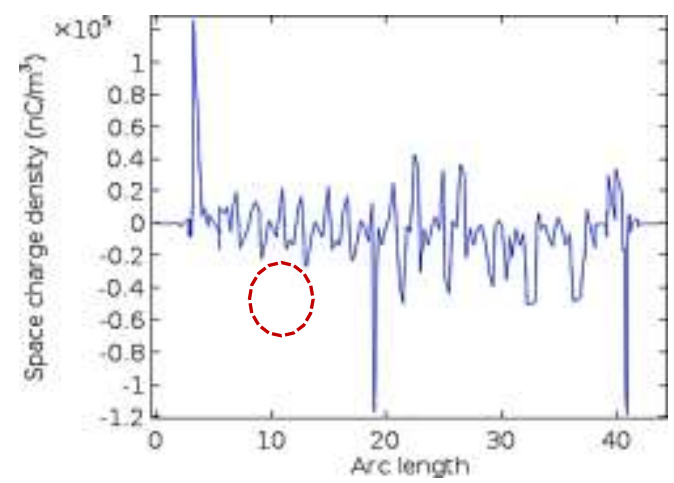

(c)

Fig. 6 - Space charge density under (a) clean;

(b) water; and (c) oil surface for SiR insulator

It can be seen from Fig. 6 that magnitude of charge achieve maximum value at both ends of the insulators. These results are consistent with (Farish and Al-Bawy, 1991) who stated that the distribution of surface charges resulting in the addition of cathode fields.

The distribution of space charge density along the insulator surface can be considered as too small which below $0.5 \times 10^{5} \mathrm{nC} / \mathrm{m}^{3}$ in clean condition as shown in Fig. 6 (a). However, it is observed that the distribution of space charge density along the insulator surface is slightly increased from the clean condition to water contamination; where the space charge density value is unstable distributed between $0.4 \times 10^{5} \mathrm{nC} / \mathrm{m}^{3}$ and more than $0.8 \times 10^{5} \mathrm{nC} / \mathrm{m}^{3}$ as circled in Fig. 6 (b). Thus, it can be concluded that the present of contamination layer on the insulator surface may trap the space charge in the layer. Interestingly, the distribution of space charge density seems much stable when the insulator was coated with oil as in Fig. 6 (c). The space charge density seems distributed around to $0.4 \times 10^{5} \mathrm{nC} / \mathrm{m}^{3}$ with only one spike of maximum value more than $1 \times 10^{5} \mathrm{nC} / \mathrm{m}^{3}$. The existence of oil on the insulator surface is believed has suppressed the movement of space charge.

\subsection{Simulation Results for EPDM Insulator}

The contour plot current density distribution under clean and contaminated for EPDM insulator is presented in Fig. 7. It is apparent from Fig. 7 that the current density seems higher distributed near to the HV electrode but lower at the ground (GND) electrode. The distribution of current density can be related to electric field that reported in (Wang, 2018) where the author applied a similar concept to outdoor insulator but in different application.

However, the electric current density in Fig. 7 (b) seems increased especially on the trunk portion between sheds and $\mathrm{HV}$ end when the insulator coated with water contamination. This condition is due to the presence of water causing the electrons move freely through the insulator surface.

Meanwhile, the increment of charge at the triple junction region of the insulator can be found in Fig. 7 (c). Generally, the oil properties have a positive charge while EPDM insulator owned negative charge. It cannot be assumed that positive charge only in the oil contamination but small amount of negative charge also exists in it. Based on the triboelectric series (Molnar, Gersimov and Kurytnik, 2018), if a material is more likely to be positive side, it can be expected to push electrons from the negative side. By applying this concept, comparison is made between EPDM and oil contamination where movement of electron charge maybe lead to the occurrence of collision and the charge increase at the critical point.

The space charge density under clean and contaminated surface condition for EPDM insulator is presented in Fig. 8. It can be seen from Fig. 6 (a) that magnitude of charge achieve maximum value at the GND end with the distribution of space charge density is more than $0.9 \times 10^{5} \mathrm{nC} / \mathrm{m}^{3}$, whereby the space charge around $0.4 \times 10^{5} \mathrm{nC} / \mathrm{m}^{3}$ is distributed along the insulator surface. Meanwhile, the space charge distribution when the insulator was coated with water seems unstable towards the GND end as seen in Fig. 6 (b); where the magnitude of charge achieves minimum value at high end of the insulator but high value is found near to GND end. The space charge density is distributed between which above $0.5 \times 10^{5}$ $\mathrm{nC} / \mathrm{m}^{3}$ above $1 \times 10^{5} \mathrm{nC} / \mathrm{m}^{3}$. Similar in Fig. 6 (c), the charge distribution seems unstable distributed along the insulator surface with the maximum value about $0.9 \times 10^{5} \mathrm{nC} / \mathrm{m}^{3}$. 


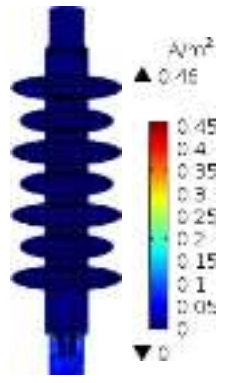

(a)

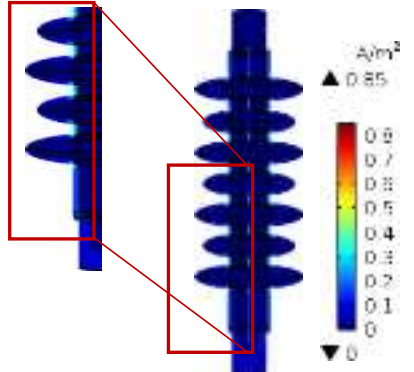

(b)

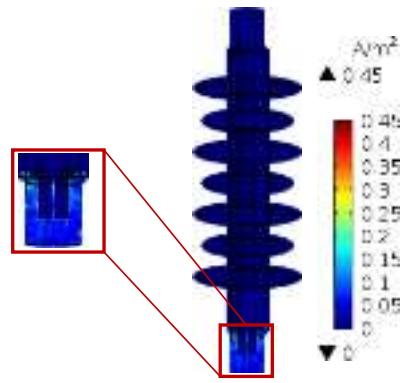

(c)

Fig. 7 - Current density contour plot under (a) clean; (b) water; and (c) oil surface condition for EPDM insulator

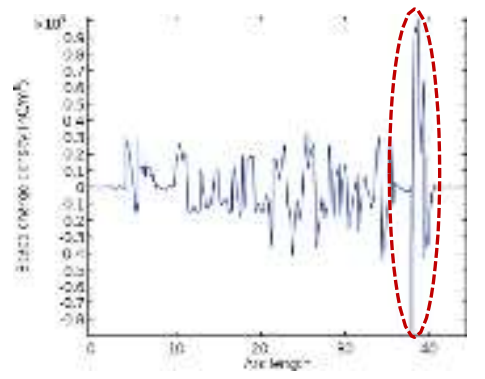

(a)

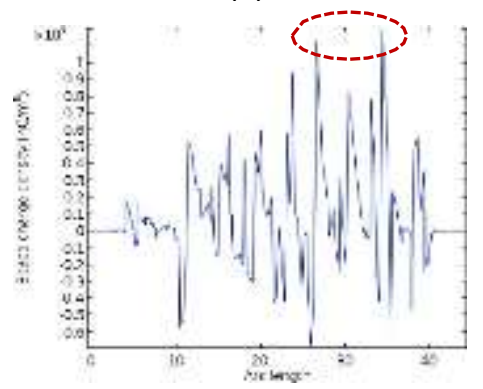

(b)

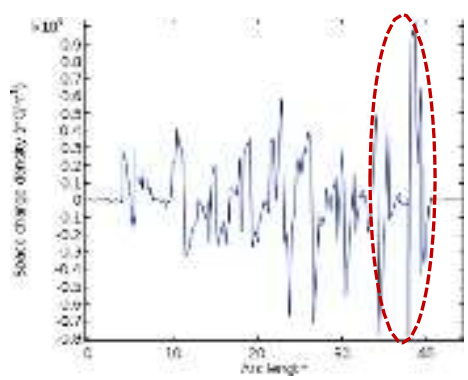

(c)

Fig. 6 - Space charge density under (a) clean; (b) water; and (c) oil surface for EPDM insulator

\subsection{Experimental Results for SiR and EPDM Insulator}

The time consuming to measure the charge distribution is an important criterion to be considered during experiment. Duration of time is crucial to make sure that the charge achieve the state of equilibrium. In this work, the time has been set to retrieve charge distribution data for 20 minutes. There are three charge sensors used in the chamber with different places namely near to GND end, HV end, and middle insulator.

Fig. 7 exhibits the results captured from experimental works on charge distribution in clean surface condition for $\mathrm{SiR}$ insulator. It can be seen from Fig. 7 that the results show that the charge sensors located near to HV end captured higher charge distribution compared to the charge sensors located near to GND end. 


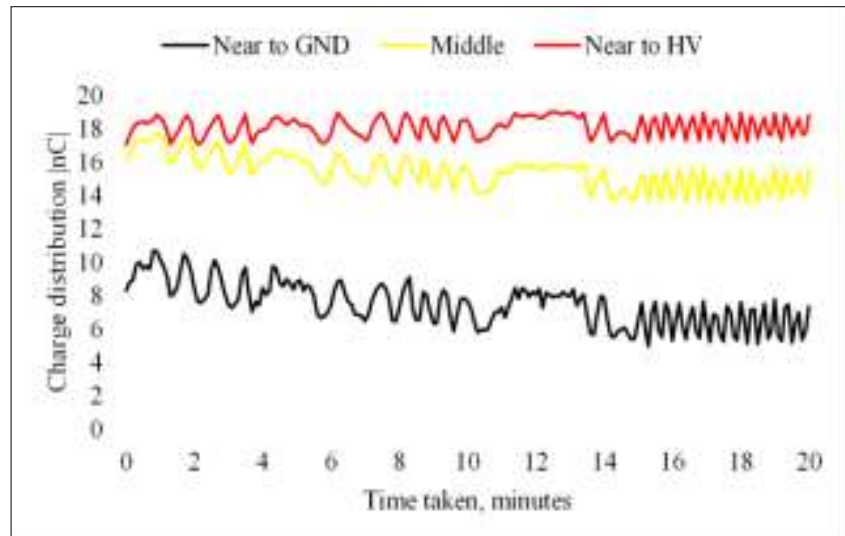

Fig. 7 - Charge amplitude in experiment for SiR insulator

Fig. 8 presents the charge distribution in clean surface condition for EPDM insulator captured from the experiment. The charge distribution pattern shown in Fig. 8 can be said similar to SiR insulator where charge is much higher at charge sensors near to HV end compared to GND end. However, the magnitude of charge seems distributed higher and more stable in EPDM insulator compared to SiR. The stability of charge in EPDM is believe due to the nature of EPDM had a longer relaxation time than SIR. (Sjostedt, Montaño, Serdyuk, and Gubański, 2007).

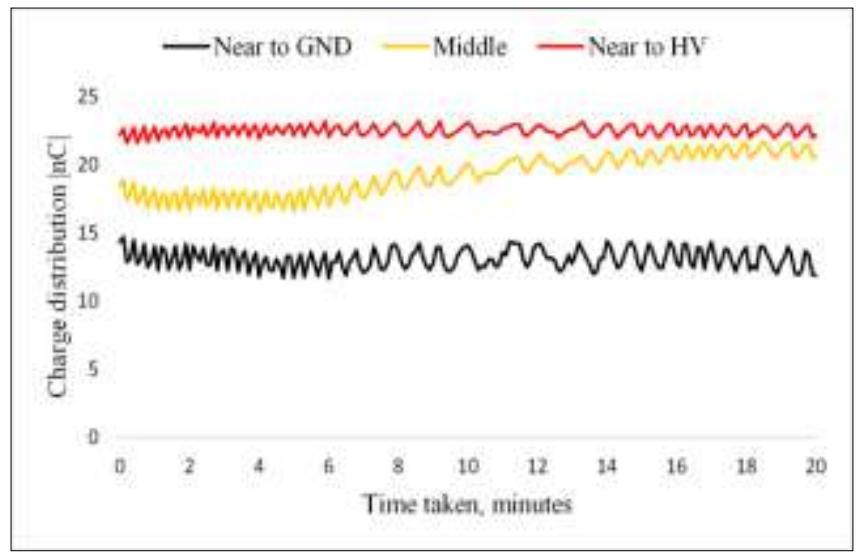

Fig. 8 - Charge amplitude in experiment for EPDM insulator

\subsection{Comparison Between SiR and EPDM}

Fig. 9 shows the comparison results on current density along the arc length under different conditions in SiR and EPDM insulator. Based on Fig. 9, the current density distribution is increased under water condition for both insulators compared to oil and clean conditions. The current findings is consistent with findings of past studies by (El-Refaie, Elrahman and Mohamed, 2016) where the conductivity of contamination give effect on the electric field value for polymeric insulator. It is accepted that the electric field is increased when the conductivity of contamination increase. The current density and electric field can be related using equation in Error! Reference source not found. and Error! Reference source not found.. It is also noticed that there is $60 \%$ and $30 \%$ difference in current density between water and oil contamination for SiR and EPDM, respectively.

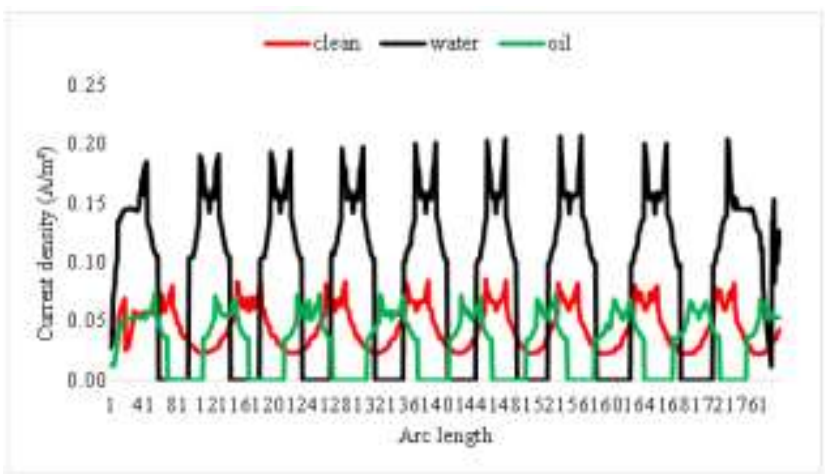

(a) 


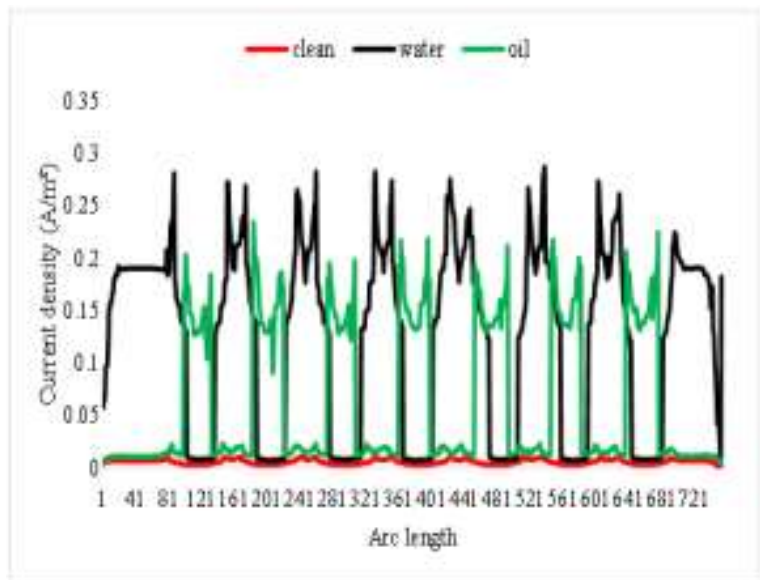

(b)

Fig. 9 - Comparison on current density under different condition in (a) SiR and (b) EPDM

Fig. 10 presents the comparison on space charge density along the arc length under three different conditions in SiR and EPDM insulator. It can be said that space charge in SiR insulator increased at the both end fitting while space charge increased at the middle of the EPDM insulator when presence the contamination on the surface. Higher magnitude of space charge density at both end fitting is believed due to the charge injection and extraction process that occurred at both ends (Tanaka and Greenwood, 1978).

It can be seen that there is $60 \%$ reduction in space charge density value when the insulator was coated with water and oil contamination for SiR insulator. However, in EPDM insulator, there is 50\% difference in space charge density between water and oil contamination.

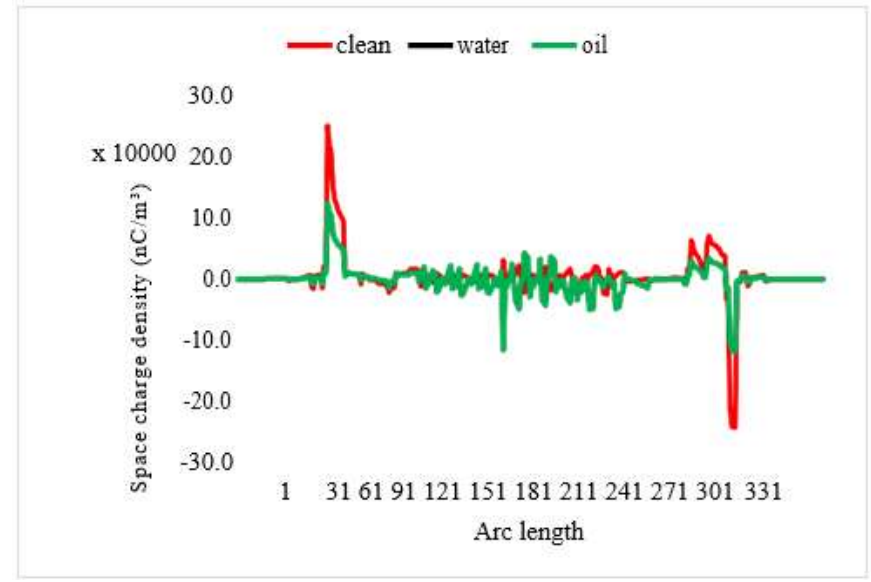

(a)

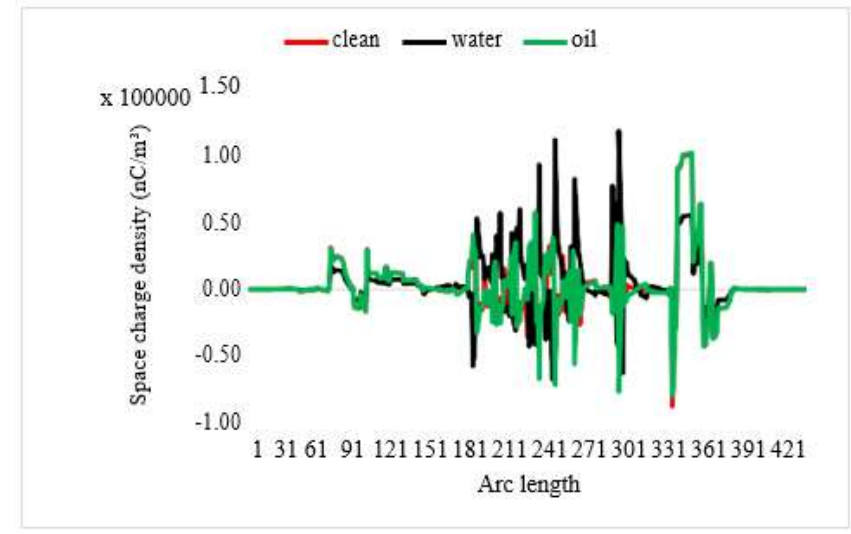

(b)

Fig. 10 - Comparison on space charge density under different condition in (a) SiR and (b) EPDM 
Fig. 11 shows that comparison of experimental results between SiR and EPDM insulators. It is apparent from Fig. 11 that the amplitude of charge for EPDM is much higher than SiR at each of charge sensors. The current finding can be considered consistent with (Arshad et al., 2016)(Sjostedt, Gubanski, and Serdyuk, 2009) where the surface resistance on $\mathrm{SiR}$ is higher than EPDM insulator in a humid environment. The relationship between conductivity and surface resistance is inversely proportional given in Fig. 11.

$$
o=1 / \rho
$$

Where, $\sigma$ is the specific conductivity of material $\rho$ is the surface resistance

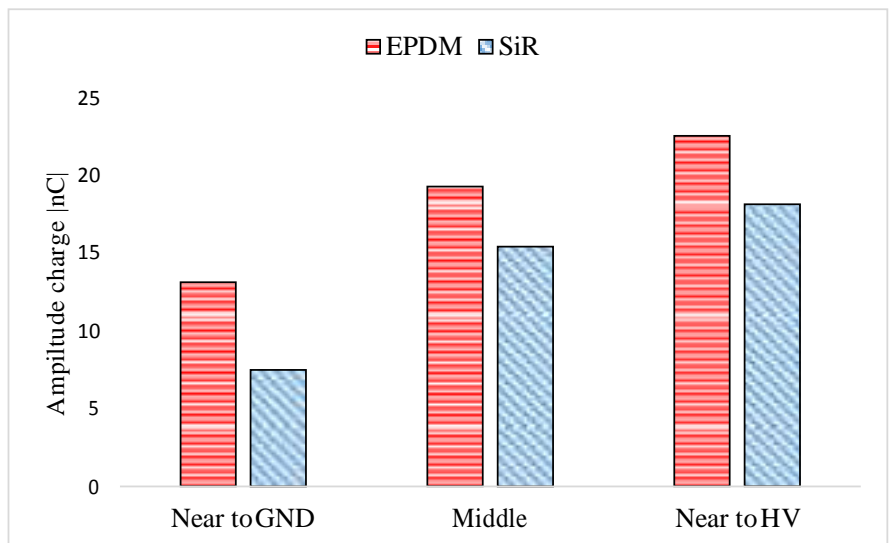

Fig. 11 - Comparison graph between SiR and EPDM in clean condition through experiment

\section{Conclusion}

Upon completion of this work, two types of insulator were chosen namely ethylene propylene-diene monomer (EPDM) and silicone rubber ( $\mathrm{SiR})$ to evaluate the current density and charge distribution on the insulator surfaces in simulation works while only charge distribution is considered in experimental works. In simulation, EPDM and SiR was designed in clean and contaminated conditions while only clean conditions is considered in experimental works. For contaminated condition, water and oil are taken into account as contamination source on the insulator surface with $15 \mathrm{kV}$ voltage injection. The following points emerged from the present investigation:

1. Current density is high in the trunk portion when encountering water on the surface insulator due to the conductivity water is higher than conductivity insulator.

2. Experiment and simulation results show that EPDM have higher amplitude of charge compared to SiR due to the tendency of conductivity of EPDM material is high. Higher conductivity may affect the surface resistance where the conductivity of insulation is inversely proportional to the surface resistance.

3. The charge amplitude distributed at each of sheds in contaminated conditions while charge amplitude distributed only at the both end-fitting in clean condition.

\section{Acknowledgement}

The authors express their sincere gratitude to Research Management Centre (RMC) of Universiti Tun Hussein Onn Malaysia (UTHM) and Universiti Teknologi Malaysia (UTM) for the use of facilities and for awarding research university grant under votes U863, U948 and 07G43 from Ministry of Education Malaysia (Higher Education).

\section{References}

[1] Arshad et al. (2016). Performance comparison of silicone rubber and EPDM insulators in humid and contaminated environments, Proc. 2016 IEEE Int. Conf. Dielectr. ICD, 2, 712-715.

[2] Davidson, I. E. (2017). Assessment of a Two Dimensional (2D) FEM Model of a $22 \mathrm{kV}$ Silicone Rubber DC Insulator, in IEEE 3rd Int. Conf. Electro-Technology Natl. Dev. Assess., 872-877.

[3] El-Refaie, E. S. M., Elrahman, M. K. A. and Mohamed, M. K. (2016). Electric field distribution of optimized composite insulator profiles under different pollution conditions, Ain Shams Eng. J. 
[4] Farish, O., and Al-Bawy, I. (1991). Effect of surface charge on impulse flashover of insulators in $\mathrm{SF}_{6}$. IEEE Transactions on Electrical Insulation, 26(3), 443-452.

[5] I. R. M. Association, Materials science and engineering: Concepts, methodologies, tools, and applications, 2017.

[6] Jamail, N. A. M., Piah, M. A. M., Muhamad, N. A., Zainir, R. A., Kasri, N. F., \& Kamarudin, Q. E. (2013). Polarization and depolarization current measurement of polymer added with nano-particles of silicon oxide for HV insulation. Jurnal Teknologi, 64(4).

[7] Khan, H., Amin, M. and Ahmad, A., (2018). Characteristics Of Silicone Composites For High Voltage Insulations. Reviews on Advanced Materials Science, 56(1), 91-123.

[8] Kroschwitz, J. I. (1990). Concise encyclopedia of polymer science and engineering (p. 1167). NY etc.: Wiley.

[9] Looms, J. S. T. and Chapman, M. C. (1991). Insulators for high voltages, IEEE Power Engineering Review, 11(6), 45-46.

[10] Mansor, N. S., Hamzah, M. S., Kamarol, M., \& Mariatti, M. (2014). A comparative study of dielectric strength between sir/epdm and pp/epdm blends with various type of nanofillers. In Advanced Materials Research,832, 483487.

[11] Marungsri, B., Onchantiek, W. and Oonsivilai, A. (2008). Electric field and potential distribution along surface of sillicone rubber polymeric insulators using finite element method, Proc. World Acad. Sci. Eng. Technol., 2(6), 6772.

[12] Mazli, A. D. A., Jamail, N. A. M. and Othman, N. A. (2017). Electric field and current density performance analysis of $\mathrm{sf}_{6}, \mathrm{c} 4 \mathrm{f} 8$ and $\mathrm{co} 2$ gases as an insulation, IOP Conf. Ser. Mater. Sci. Eng., 226(1).

[13] Molnar, O., Gersimov, V. and Kurytnik, I. P. (2018). Triboelectricity and construction of power generators based on it, Przegląd Elektrotechniczny, 1(1), 169-173.

[14] Moussavi, S.Z., Sheikhdoragh, B. and Shayegani-Akmal, A.A., (2012). Investigation on pollution factors on electric field and potential distribution of polymeric insulator. J. Basic. Appl. Sci. Res, 2, 12482-12491.

[15] Muniraj, C. and Chandrasekar, S. (2012). Finite element modeling for electric field and voltage distribution along the polluted polymeric insulator, World J. Model. Simul, 70(4), 310-320.

[16] Nekahi, A., McMeekin, S. G., \& Farzaneh, M. (2015). Effect of dry band location on electric field distribution along a polymeric insulator under contaminated conditions. In 2015 50th International Universities Power Engineering Conference (UPEC), 1-4.

[17] Norddin, N. et al. (2013). Polymeric insulation surface condition analysis using linear time frequency distributions, Power Eng. Optim. Conf. (PEOCO), 558-563.

[18] Othman, N. A., Piah, M. A. M., and Adzis, Z. (2017). Charge distribution measurement of solid insulator materials: A review and new approach, Renewable and Sustainable Energy Reviews. Elsevier, 70(November 2016), 413-426. doi: 10.1016/j.rser.2016.11.237.

[19] Rahman, M. and Thottappillil, R. (2002). Comment on Effect of surface charge on hydrophobicity levels of insulating materials, IEE Proc.-Gener. Transm. Distrib., 149(3).

[20] Sarang, B., Lakdawala, V., \& Basappa, P. (2009). Electric field calculations on a high voltage insulator under wet conditions. In 2009 IEEE Electrical Insulation Conference, 86-90.

[21] Shazly, J. H., Mostafa, M. A., Ibrahim, D. K., \& El Zahab, E. E. A. (2017). Thermal analysis of high-voltage cables with several types of insulation for different configurations in the presence of harmonics. IET Generation, Transmission and Distribution, 11(14), 3439-3448. 
[22] Sjostedt, H., Montaño, R., Serdyuk, Y. and Gubański, M., (2007). Charge relaxation on surfaces of polymeric insulating materials for outdoor applications. Prace Naukowe Instytutu Podstaw Elektrotechniki $i$ Elektrotechnologii Politechniki Wrocławskiej. Konferencje, 46(19), 17-20.

[23] Sjostedt, H., Gubanski, S. M., \& Serdyuk, Y. V. (2009). Charging characteristics of EPDM and silicone rubbers deduced from surface potential measurements. IEEE Transactions on Dielectrics and Electrical Insulation, 16(3), 696-703.

[24] Tanaka, T., \& Greenwood, A. (1978). Effects of charge injection and extraction on tree initiation in polyethylene. IEEE Transactions on Power Apparatus and Systems, (5), 1749-1759.

[25] Wang, X. (2018). Study on charge migration properties at XLPE/EPDM interface under orthogonal electric field, in Proc. IEEE Int. Conf. Prop. Appl. Dielectr. Mater., 239-244. 